Published in final edited form as:

Trends Cogn Sci. 2010 March ; 14(3): 110-118. doi:10.1016/j.tics.2009.12.006.

\title{
False-belief understanding in infants
}

\author{
Renée Baillargeon, Rose M. Scott, and Zijing He \\ Department of Psychology, University of Illinois, Champaign, IL 61820, USA
}

\begin{abstract}
At what age can children attribute false beliefs to others? Traditionally, investigations into this question have used elicited-response tasks in which children are asked a direct question about an agent's' false belief. Results from these tasks indicate that the ability to attribute false beliefs does not emerge until about age 4 . However, recent investigations using spontaneous-response tasks suggest that this ability is present much earlier. Here we review results from various spontaneousresponse tasks which suggest that infants in the second year of life can already attribute false beliefs about location and identity as well as false perceptions. We also consider alternative interpretations that have been offered for these results, and discuss why elicited-response tasks are particularly difficult for young children.
\end{abstract}

\section{When do children first attribute false beliefs to others?}

As adults, we routinely interpret others' behavior in terms of underlying mental states. Thus, we readily understand that Cinderella wants to go to the ball, does not know her fairy godmother will soon arrive to make her dreams come true, and falsely believes she will spend yet another evening mending clothes by the hearth. Developmental psychologists have long been interested in how the ability to attribute mental states to others develops in children.

In particular, a great deal of research has focused on the question of when children first understand that agents may hold and act on false beliefs. This question is important for two interrelated reasons. First, false-belief understanding provides evidence for a sophisticated (and possibly uniquely human) ability to consider the information available to an agent when interpreting and predicting the agent's actions-even if this information is inaccurate and incompatible with one's own [1,2]. Second, the age at which children first attribute false beliefs signals the age at which the psychological-reasoning subsystem necessary for computing such mental states becomes operational [3,4] (see Box 1).

Initial investigations of children's false-belief understanding used elicited-response tasks in which children answer a direct question about an agent's false belief [2,5-7]. In one classic task [5], children listen to the following story enacted with props: Sally hides a marble in a basket and then leaves; in her absence, Ann moves the marble to a nearby box. Children are then asked where Sally will look for her marble when she returns. Beginning at about age 4, children typically answer correctly and point to the basket (where Sally falsely believes the toy is); in contrast, most 3-year-olds point to the box (where the toy actually is), suggesting that they do not yet understand that Sally will have a false belief. This developmental pattern has been confirmed with tasks testing different false beliefs $[8,9]$ and with children from different

Corresponding author: Baillargeon, R. (rbaillar@illinois.edu).

Publisher's Disclaimer: This is a PDF file of an unedited manuscript that has been accepted for publication. As a service to our customers we are providing this early version of the manuscript. The manuscript will undergo copyediting, typesetting, and review of the resulting proof before it is published in its final citable form. Please note that during the production process errors may be discovered which could affect the content, and all legal disclaimers that apply to the journal pertain. 
countries $[10,11]$. These highly consistent results have led many researchers to conclude that the ability to attribute false beliefs to others does not emerge until about 4 years of age [12-15].

However, recent investigations using spontaneous-response tasks suggest that this ability may be present much earlier. In these tasks, children's understanding of an agent's false belief is inferred from behaviors they spontaneously produce as they observe a scene unfold (just as adults watching a movie may spontaneously produce responses that reveal their understanding of the characters' mental states). Spontaneous-response tasks currently include violation-ofexpectation (VOE) and anticipatory-looking (AL) tasks. VOE tasks test whether children look reliably longer when agents act in a manner that is inconsistent, as opposed to consistent, with their false beliefs. AL tasks examine whether children visually anticipate where an agent with a false belief about the location of an object will search for the object. To date, spontaneousresponse tasks have shown that infants can attribute to an agent a false belief about an object's location [16-19], a false perception of an object [21], and a false belief about an object's identity [4]; these findings are described below.

\section{Findings from spontaneous-response false-belief tasks}

\section{False belief about location}

In a VOE experiment, Onishi and Baillargeon [16] examined whether 15-month-olds could attribute to an agent a false belief about the location of an object (Figure 1). In the first familiarization trial, a toy stood between a yellow and a green box; a female agent entered the apparatus, played with the toy briefly, hid it inside the green box, and then paused, with her hand inside the green box, until the trial ended. In the second and third familiarization trials, the agent reached inside the green box (as though to grasp her toy) and then paused. Next, the infants received a belief-induction trial that varied across conditions. For example, in the falsebelief-green condition, the toy moved from the green to the yellow box in the agent's absence; in the false-belief-yellow condition, the toy moved to the yellow box in the agent's presence, but then returned to the green box after she left. Finally, during the test trial, the agent reached inside either the yellow (yellow-box event) or the green (green-box event) box and then paused. In each condition, the infants expected the agent to reach where she falsely believed the toy to be hidden, and they looked reliably longer when she reached to the other location instead. Thus, in the false-belief-green condition, the infants who saw the yellow-box event looked reliably longer than those who saw the green-box event; in the false-belief-yellow condition, this looking-pattern reversed. (Most tasks in this review included control conditions in which the agent knew the toy's location and infants expected the agent to act in accordance with this knowledge; due to space limitations, these knowledge conditions are not described here).

Subsequent VOE investigations confirmed [20] and extended the results of Onishi and Baillargeon [16] in several ways. Surian, Caldi, and Sperber [19] provided evidence that even 13-month-olds can attribute to an agent a false belief about the location of an object, and that this agent need not be human. In the familiarization trials, a caterpillar watched an experimenter's hand hide an apple behind one screen and a piece of cheese behind another screen; the caterpillar always approached the same screen to chew on the same, preferred food. In the test trial, the hand hid the two food items in the reverse locations before the caterpillar entered the scene. The infants looked reliably longer when the caterpillar approached the new location, suggesting that they expected the caterpillar to falsely assume that its preferred food was hidden in the same location as before. Song, Onishi, Baillargeon, and Fisher [17] showed that 18-month-olds realize that an agent's false belief about an object's location can be corrected by an appropriate, though not an inappropriate, communication. In one experiment, for example, a female agent hid a ball in a box and was absent when an experimenter moved it to a cup. When the agent returned, the infants expected her to search in the cup if the experimenter 
told her "The ball is in the cup!", but to search in the box if the experimenter told her "I like the cup!", as though they recognized that only the first utterance could correct the agent's false belief about the ball's location.

Finally, building on prior AL results with 3-year-olds [22,23], Southgate, Senju, and Csibra [18] showed in a non-verbal AL task that 25-month-olds can correctly anticipate where an agent with a false belief will search for an object. In the familiarization trials, a bear puppet hid a toy in one of two boxes while a female agent looked on; her head was visible above a panel with two small doors, one above each box. After the bear hid the toy, the two doors lit up; the agent then opened the correct door to retrieve the toy. In the test trial, the agent saw the bear hide the toy in the left or the right box. A phone then rang behind the agent, who turned toward the sound; while she was facing away, the bear retrieved the toy and left with it. The phone then stopped ringing, the agent turned toward the boxes, and the doors lit up. Most infants correctly anticipated the agent's behavior and looked at the door above the box where she falsely believed the toy to be hidden.

\section{False perception}

A false perception is an erroneous conclusion, based on misleading perceptual information, about what type of object one is facing (e.g., a grandmother or a wolf dressed in her nightclothes, in Little Red Riding Hood). Song and Baillargeon [21] examined whether 14.5month-olds could attribute to an agent a false perception of an object (Figure 2). In the familiarization trials, a female agent sat behind two toys: a doll with blue pigtails, and a stuffed skunk with a pink bow. Across trials, an experimenter's hands placed the toys on placemats or inside shallow containers; the agent always reached for either the doll (doll condition) or the skunk (skunk condition), suggesting that she preferred it over the other toy. In the next, boxorientation trial, the agent was absent; two large boxes with lids rested on the apparatus floor and the experimenter demonstrated that the right box's lid had a tuft of blue hair (similar to the doll's) attached to it. At the start of the test trial, the agent was again absent; the experimenter hid the doll in the plain box and the skunk in the hair box. The agent then returned, reached for either the plain or the hair box, and then paused. In each condition, the infants expected the agent (1) to falsely perceive the tuft of hair as belonging to the doll; (2) to falsely conclude that the doll was hidden in the hair box and the skunk in the plain box (since both toys had always been present in the preceding trials); and (3) to search for her preferred toy accordingly. Thus, in the doll condition, the infants expected the agent to reach for the hair box and looked reliably longer when she reached for the plain box instead; conversely, in the skunk condition, the infants expected the agent to reach for the plain box and looked reliably longer when she reached for the hair box.

\section{False belief about identity}

A false belief about identity is an erroneous conclusion, based on misleading contextual information, about what object token one is facing (e.g., Fred or George Weasley, in Harry Potter). Scott and Baillargeon [4] examined whether 18-month-olds could attribute to an agent a false belief about the identity of an object (Figure 3). The familiarization trials involved two identical toy penguins; one could come apart (2-piece penguin) and one could not (1-piece penguin). In each trial, as a female agent watched, an experimenter's hands placed the 1-piece penguin and the two pieces of the disassembled 2-piece penguin on platforms or in shallow containers (the experimenter never stacked the 2-piece penguin in these trials). The agent then placed a key in the bottom piece of the 2-piece penguin and stacked the two pieces; the two penguins were then indistinguishable. During the test trials, while the agent was absent, the experimenter assembled the 2-piece penguin, covered it with a transparent cover, and then covered the 1-piece penguin with an opaque cover. The agent then entered the apparatus with her key and reached for either the transparent or the opaque cover. The infants looked reliably 
longer when the agent reached for the transparent as opposed to the opaque cover, suggesting that they expected her (1) to falsely assume that the penguin under the transparent cover was the 1-piece penguin (since the 2-piece penguin was always disassembled at the start of the preceding trials); (2) to falsely conclude that the disassembled 2-piece penguin was under the opaque cover (since both penguins were always present in previous trials); and hence (3) to reach for the opaque cover. Support for this interpretation came from a knowledge condition (where the agent was present throughout the test trial and thus knew the 2-piece penguin was under the transparent cover) and an ignorance condition (see Figure 4).

\section{Summary}

The evidence reviewed above suggests that infants in the second year of life can already attribute false beliefs to others (see Boxes 2 and 3 for alternative interpretations). This ability is quite robust: it can be demonstrated with different spontaneous-response tasks, with various belief-inducing situations, and with human and non-human agents. Moreover, infants recognize that an agent can hold a false belief about an object's location because (1) it is moved to another hiding location in the agent's absence or (2) it is hidden in the agent's absence and misleading perceptual or contextual cues cause the agent to incorrectly infer its likely location. Finally, infants can attribute to an agent a complex set of mental states that includes multiple false beliefs. To illustrate, consider once again the skunk condition of Song and Baillargeon [21]. To respond correctly in the test trial, the infants had to reason that the agent had a particular disposition, a preference for the skunk over the doll, which would lead her to form the goal of obtaining the skunk. The infants also had to consider the agent's knowledge about the scene: they had to attribute to the agent not only the ability to notice the boxes and tuft of hair, but also to correctly infer that the doll and skunk were both present, as in the preceding trials, and hidden in the boxes. Finally, the infants had to reason that the agent's false perception of the tuft of hair as a part of the doll would lead her to hold false beliefs about the locations of the doll and skunk.

\section{Why do young children fail at elicited-response false-belief tasks?}

Given the findings reviewed above, young children are unlikely to fail elicited-response falsebelief tasks because they cannot represent false beliefs (due to conceptual, linguistic, executivefunction, or other limitations). Why, then, do they fail?

According to our response account [4], elicited-response tasks involve at least three processes: (1) a false-belief-representation process, carried out by SS2 in the psychological-reasoning system (children must represent the agent's false belief); (2) a response-selection process (when asked the test question, children must access their representation of the agent's false belief to select a response); and (3) a response-inhibition process (when selecting a response, children must inhibit any prepotent tendency to answer the test question based on their own knowledge) [24-29]. Spontaneous-response tasks, in contrast, involve only the false-belief-representation process. Young children fail elicited-response tasks because simultaneously executing the false-belief-representation, response-selection, and response-inhibition processes overwhelms their limited resources, and/or because the connections between the brain regions that serve these processes are still inefficient. Neuroscience findings suggest that (1) the right temporoparietal junction plays an important role in the false-belief-representation process [30-33]; (2) regions of the anterior cingulate and prefrontal cortex play an important role in the responseselection process [34-37]; and (3) the connections between the frontal and temporal brain regions mature later and more slowly than other connections [38]. Thus, it could be that, in early childhood, the response-selection process has difficulty tapping the false-beliefrepresentation process (SS2) because the connections between the relevant brain regions are still immature. 
The response account predicts that toddlers should succeed at various false-belief tasks (see Box 4). In addition, the response account predicts that infants should succeed at indirectelicited-response tasks that require them to answer questions or prompts that do not directly tap their representation of an agent's false belief. Two such tasks have been reported to date. In Buttelmann, Carpenter, and Tomasello [39], an experimenter showed 18-month-olds two lidded boxes and demonstrated how to lock and unlock them; the boxes were left unlocked. Next, a male agent entered the room, hid a toy in one of the boxes, and then left. While he was gone, the experimenter moved the toy to the other box and locked both boxes. When the agent returned, he tried to open the box where he had hidden the toy, without success, and then sat centered behind the boxes. When prompted to help the agent, most infants approached the other box (i.e. the one the agent did not act on), suggesting that they realized the agent falsely believed the toy was still in its original location and wanted to retrieve it. In Southgate, Chevallier, and Csibra [40], 17-month-olds watched as a female agent hid two different toys in two lidded boxes and then left. While she was gone, an experimenter switched the toys. The agent then returned, pointed to one of the boxes, and announced that the toy inside it was a "sefo". When prompted to get the sefo, most infants approached the other box (i.e. the one the agent did not point to), suggesting that they realized the agent falsely believed the toys were still in their original locations and meant to refer to the toy in the other box as a sefo.

According to the response account, the infants in these indirect-elicited-response tasks represented the agent's false belief and used this representation to infer what goal the agent was trying to achieve [39] or which object was the sefo [40]. To respond correctly when prompted, the infants only needed to consult this additional information: they did not have to tap their representation of the agent's false belief directly, as they would have if asked which box the agent would approach to retrieve his toy or her sefo.

\section{Concluding remarks}

Contrary to traditional claims, the ability to attribute false beliefs to others is already present by the second year of life. When tested with VOE, AL, helping, and referential-communication tasks, infants attribute to agents false beliefs about location and identity as well as false perceptions. Many questions remain, however, about the development of false-belief understanding in infancy and early childhood-Box 4 outlines some of the questions currently being explored in various laboratories.

\section{Box 1}

\section{Subsystem-1 and subsystem-2 in infants' psychological-reasoning system}

Like several other researchers, we assume that infants are born with a psychologicalreasoning system that provides them with a skeletal causal framework for interpreting the actions of agents [3,41-43]. Common assumptions about this system are that: it operates without conscious awareness [17,44]; it applies to human or non-human agents [19, 45-49]; it is constrained by core principles such as rationality (agents pursue their goals in causally appropriate and efficient ways) $[41,45,50,51]$; and it involves at least two subsystems, Subsystem-1 (SS1) and Subsystem-2 (SS2) [3]. Below is our description of these subsystems [4].

\section{Subsystem-1}

When infants watch an agent act in a scene, SS1 enables them to attribute at least two kinds of mental states to the agent: motivational states, which specify the agent's motivation in the scene (e.g., goals, dispositions), and reality-congruent informational states, which specify what accurate information the agent can gather about the scene through perception, memory, or inference (e.g., knowledge, ignorance). When the agent's representation of the 
scene is incomplete relative to that of the infant (e.g., the agent cannot see an object that the infant sees), a masking mechanism blocks the information that is not available to the agent, enabling the infant to interpret or predict the agent's actions in terms of the remaining, shared information. SS1 is already operational in the first months of life and is well in place by the end of the first year [45-57].

\section{Subsystem-2}

SS2 extends SS1 and enables infants to attribute to agents reality-incongruent informational states; these include false beliefs as well as pretense [58,59]. When an agent's representation of a scene is incompatible with that of the infant (e.g., the agent believes toy$\mathrm{A}$ is in location-A and toy-B is in location-B, but the infant knows the toys' locations have been switched), SS2 allows the infant to represent these divergent beliefs. A decoupling mechanism enables the infant to hold in mind a separate representation of the scene that incorporates the agent's false or pretend beliefs but otherwise functions as expected, making it possible to interpret or predict the agent's actions [32,59]. The evidence summarized in this review suggests that SS2 is already operational in the second year of life.

\section{Box 2}

\section{Two alternative interpretations: associations and unusual events}

Two of the alternative interpretations that have been offered for the false-belief findings with infants invoke low-level processes.

According to the association interpretation proposed by Perner and Ruffman [60,61; see also Ref. 62], when infants in VOE, AL, and helping tasks watch agents act on objects, they form associations that encode "configurations of persons relating to objects" [60, p. 462]; these associations then guide infants' responses. For example, when infants in a VOE task see familiarization events in which an agent hides a toy in one location, they form an association linking the agent, the toy, and its hiding location; this association then leads the infants to look longer when a test event deviates from the association (e.g., when the agent searches for the toy in a different location). However, numerous experiments on SS1 mental states contradict the notion that infants merely form associations [44-56; see also Ref. 63]. For instance, in many VOE tasks, infants in one condition look longer at the test event that deviates from the familiarization events, but infants in other, very similar conditions do not. To illustrate, after watching familiarization events in which an agent repeatedly grasps object-A, infants look longer in test if the agent now grasps object-B, but only if object-B is both present and visible to the agent during the familiarization events, so that infants have evidence that the agent prefers object-A over object-B [48,53,54,64]. These different looking-patterns indicate that infants do not merely form associations but consider (at the very least) the motivational and reality-incongruent informational states that underlie agents' actions.

According to the unusual-event interpretation suggested by Buttelmann et al. [39], infants in VOE false-belief tasks do not really attribute false beliefs to agents: they merely "take special notice of unusual events" [38, p. 2]. This interpretation is derived from Haith's [65] controversial claim that infants look longer at unexpected events in VOE physicalreasoning tasks simply because these events (e.g., an object floating in midair) are odd or unusual (for a rejoinder, see [66]). Haith's claim cannot be extended to VOE false-belief tasks, however, because the unexpected events in these tasks (e.g., an agent reaching for a box) are in no way odd or unusual. Indeed, in many VOE false-belief tasks, the event that is unexpected in one false-belief condition is the same event that is expected in another 
false-belief condition. Across conditions, events are unexpected only because they depict agents who fail to act in accordance with their false beliefs.

\section{Box 3}

\section{Two alternative interpretations: ignorance and behavioral rules}

Two of the alternative interpretations offered for the false-belief findings with infants assume that infants are capable of attributing SS1 but not SS2 mental states to agents.

According to the ignorance interpretation, infants bring to the laboratory general expectations about how ignorant agents behave. This interpretation has two versions. The error version [18] suggests that infants expect ignorance to lead to error: if an agent is absent when an object is moved from location-A to location- $\mathrm{B}$, infants expect the agent to search in the incorrect location, location-A. In the uncertainty version offered by Wellman [15], infants expect ignorance to lead to uncertainty, rather than to error: they are surprised if an ignorant agent approaches location-B confidently, as opposed to tentatively, as would befit an ignorant agent. Evidence against both versions comes from VOE tasks in which agents are ignorant as opposed to mistaken. For example, Scott and Baillargeon [4] conducted an ignorance experiment identical to their false-belief experiment except that in the test trials the penguins were both hidden under opaque covers (Figure 4). The infants looked about equally when the agent reached for either cover, as though they realized that she could not know which cover hid the 2-piece penguin (infants in a control experiment did remember where the 2-piece penguin was hidden). These results indicate that the infants in the falsebelief experiment did not merely expect the agent to look for her 2-piece penguin in the incorrect location (contradicting the error version), and were not simply surprised when the agent reached confidently in the correct location (contradicting the uncertainty version).

According to the behavioral-rule interpretation proposed by Perner and Ruffman [60,61], infants bring to the laboratory behavioral rules about how ignorant agents typically behave in specific situations (e.g., search for hidden objects). To test this interpretation, researchers are examining false-belief understanding in varied situations (e.g., infants reason about how an agent should go about reproducing an effect or deceiving another agent). As more and more rules are required to account for positive results, the claim that most infants come to the laboratory equipped with the same extensive list of acquired rules becomes less plausible. In addition, researchers are exploring situations where infants expect an agent not to follow a behavioral rule because the agent has information-now outdated and hence false- that the rule does not apply in the situations. If the behavioral-rule interpretation must concede that infants sometimes expect agents to act on false information, it does not provide a viable alternative account of the false-belief findings with infants.

\section{Box 4}

\section{Outstanding questions}

- Can infants in the first year of life attribute false beliefs to agents? At what age does SS2 become operational?

- Do infants and toddlers from different countries consistently succeed at spontaneous-response false-belief tasks, just as they consistently fail at elicitedresponse false-belief tasks?

- Do autistic toddlers have difficulties with spontaneous-response false-belief tasks, just as they have difficulties with elicited-response false-belief tasks? 
- In VOE tasks, 2.5-year-olds attribute to agents false beliefs about objects' location or contents [67]. Since toddlers have richer linguistic and behavioral abilities than infants, what other spontaneous-response false-belief tasks can be developed that take advantage of these abilities?

- Finally, is the response account correct? Ongoing experiments are testing various predictions from the account. For example, one prediction is that toddlers should succeed at a VOE task in which they observe an adult "participant" receive a SallyAnn task (i.e. they should look longer when the "participant" mistakenly points to the toy's current location, rather than to its original location). Another prediction involves a low-inhibition Sally-Ann task (Ann takes the marble away, instead of moving it to the other location). Although response-inhibition demands are substantially reduced in this task (since children do not know the marble's current location), performance is still at chance [2,7], presumably because of responseselection demands. The response account predicts that toddlers might succeed at the task if given practice trials designed to decrease these response-selection demands.

\section{Acknowledgments}

The redaction of this review was supported by a grant from NICHD to Renée Baillargeon (HD-021104) and by a predoctoral traineeship from NIMH (1 T32MH1819990) to Rose M. Scott.

\section{References}

1. Call J, Tomasello M. Does the chimpanzee have a theory of mind? 30 years later. Trends Cognit Sci 2008;12:187-192. [PubMed: 18424224]

2. Wimmer H, Perner J. Beliefs about beliefs: Representation and constraining function of wrong beliefs in young children's understanding of deception. Cognition 1983;13:103-128. [PubMed: 6681741]

3. Leslie, AM. ToMM, ToBy, and Agency: Core architecture and domain specificity. In: Hirschfield, L.; Gelman, S., editors. Domain Specificity in Culture and Cognition. Cambridge University Press; 1994. p. 119-148.

4. Scott RM, Baillargeon R. Which penguin is this? Attributing false beliefs about identity at 18 months. Child Dev 2009;80:1172-1196. [PubMed: 19630901]

5. Baron-Cohen S, et al. Does the autistic child have a "theory of mind"? Cognition 1985;21:37-46. [PubMed: 2934210]

6. Wellman HM, Bartsch K. Young children's reasoning about beliefs. Cognition 1988;30:239-277. [PubMed: 3215003]

7. Wellman HM, et al. Meta-analysis of theory-of-mind development: The truth about false belief. Child Dev 2001;72:655-684. [PubMed: 11405571]

8. Gopnik A, Astington JW. Children's understanding of representational change and its relation to the understanding of false belief and the appearance-reality distinction. Child Dev 1988;59:26-37. [PubMed: 3342716]

9. Perner J, et al. Three-year-olds' difficulty with false belief: The case for a conceptual deficit. Br J Dev Psychol 1987;5:125-137.

10. Callaghan T, et al. Synchrony in the onset of mental-state reasoning. Psychol Sci 2005;16:378-384. [PubMed: 15869697]

11. Liu D, et al. Theory of mind development in Chinese children: A meta-analysis of false-belief understanding across cultures and languages. Dev Psychol 2008;44:523-531. [PubMed: 18331141]

12. Gopnik, A.; Wellman, HM. The “theory theory.”. In: Hirschfield, L.; Gelman, S., editors. Domain Specificity in Culture and Cognition. Cambridge University Press; 1994. p. 257-293.

13. Perner, J. Understanding the representational mind. MIT Press; 1991. 
14. Tager-Flusberg, H. What neurodevelopmental disorders can reveal about cognitive architecture: the example of theory of mind. In: Carruthers, P.; Laurence, S.; Stitch, S., editors. The Innate Mind: Structure and Contents. Oxford University Press; 2005. p. 272-288.

15. Wellman, H. Developing a theory of mind. In: Goswami, U., editor. The Blackwell Handbook of Cognitive Development. 2nd. Blackwell; in press

16. Onishi KH, Baillargeon R. Do 15-month-old infants understand false beliefs? Science 2005;308:255258. [PubMed: 15821091]

17. Song H, et al. Can an agent's false belief be corrected through an appropriate communication? Psychological reasoning in 18-month-old infants. Cognition 2008;109:295-315. [PubMed: 18976745]

18. Southgate V, et al. Action anticipation through attribution of false belief by two-year-olds. Psychol Sci 2007;18:587-592. [PubMed: 17614866]

19. Surian L, et al. Attribution of beliefs to 13-month-old infants. Psychol Sci 2007;18:580-586. [PubMed: 17614865]

20. Träuble B, et al. Early theory of mind competencies: Do infants understand false belief? Infancy. in press.

21. Song H, Baillargeon R. Infants' reasoning about others' false perceptions. Dev Psychol 2008;44:1789_ 1795. [PubMed: 18999340]

22. Clements WA, Perner J. Implicit understanding of belief. Cognit Dev 1994;9:377-395.

23. Garnham WA, Ruffman T. Doesn't see, doesn't know: Is anticipatory looking really related to understanding of belief? Dev Sci 2001;4:94-100.

24. Birch SAJ, Bloom P. Children are cursed: An asymmetric bias in mental-state attribution. Psychol Sci 2003;14:283-286. [PubMed: 12741755]

25. Hala $\mathrm{S}$, et al. Executive functioning and false-belief understanding in preschool children: Two tasks are harder than one. J Cogn Dev 2003;4:275-298.

26. Kikuno H, et al. How do young children process beliefs about beliefs? Evidence from response latency. Mind Lang 2007;22:297-316.

27. Kovács ÁM. Early bilingualism enhances mechanisms of false-belief reasoning. Dev Sci 2009;12:4854. [PubMed: 19120412]

28. Moses, LJ., et al. On the specificity of the relation between executive function and children's theory of mind. In: Schneider, W.; Schumann-Hengsteler, R.; Sodian, B., editors. Young children's cognitive development: Interrelations among executive functioning, working memory, verbal ability and theory of mind. Lawrence Erlbaum Associates; 2005. p. 131-145.

29. Roth D, Leslie AM. Solving belief problems: A task analysis. Cognition 1998;66:1-31. [PubMed: 9675976]

30. Kobayashi C, et al. Children's and adults' neural bases of verbal and nonverbal 'theory of mind'. Neuropsychologia 2007;45:1522-1532. [PubMed: 17208260]

31. Perner J, et al. Thinking of mental and other representations: The roles of left and right temporoparietal junction. Soc Neurosci 2006;1:245-258. [PubMed: 18633791]

32. Saxe R, Wexler A. Making sense of another mind: The role of the right temporo-parietal junction. Neuropsychologia 2005;43:1391-1399. [PubMed: 15936784]

33. Sommer M, et al. Neural correlates of true and false belief reasoning. Neuroimage 2007;35:13781384. [PubMed: 17376703]

34. Herwig A, et al. Two modes of sensorimotor integration in intention-based and stimulus-based action. Q J Exp Psychol 2007;60:1540-1554.

35. Mueller VA, et al. The role of the preSMA and the rostral cingulated zone in internally selected actions. Neuroimage 2007;37:1354-1361. [PubMed: 17681798]

36. Obhi SS, Haggard P. Internally generated and externally triggered actions are physically distinct and independently controlled. Exp Brain Res 2004;156:518-523. [PubMed: 15167978]

37. Waszak F, et al. Intention-based and stimulus-based mechanisms in action selection. Exp Brain Res 2005;162:346-356. [PubMed: 15599722]

38. Lebel C, et al. Microstructural maturation of the human brain from childhood to adulthood. Neuroimage 2008;40:1044-1055. [PubMed: 18295509] 
39. Buttelmann D, et al. Eighteen-month-old infants show false belief understanding in an active helping paradigm. Cognition 2009;112:337-342. [PubMed: 19524885]

40. Southgate V, et al. (in press) Seventeen-month-olds appeal to false beliefs to interpret others' referential communication. Dev Sci.

41. Gergely G, Csibra G. Teleological reasoning in infancy: The naïve theory of rational action. Trends Cognit Sci 2003;7:287-292. [PubMed: 12860186]

42. Johnson, SC. Reasoning about intentionality in preverbal infants. In: Carruthers, P.; Laurence, S.; Stitch, S., editors. The Innate Mind: Structure and Contents. Oxford University Press; 2005. p. 254-271.

43. Premack, D.; Premack, AJ. Origins of human social competence. In: Gazzaniga, MS., editor. The cognitive neurosciences. MIT Press; 1995. p. 205-218.

44. Leslie, AM. How to acquire a 'representational theory of mind'. In: Sperber, D., editor. Metarepresentations: An Multidisciplinary perspective. Oxford University Press; 2000. p. 197-223.

45. Csibra G. Goal attribution to inanimate agents by 6.5-month-old infants. Cognition 2008;107:705717. [PubMed: 17869235]

46. Hamlin JK, et al. Social evaluation by preverbal infants. Nature 2007;450:557-559. [PubMed: 18033298]

47. Johnson SC, et al. Actors and actions: The role of agent behavior in infants' attribution of goals. Cognit Dev 2007;22:310-322. [PubMed: 18591991]

48. Luo Y, Baillargeon R. Can a self-propelled box have a goal? Psychological reasoning in 5-monthold infants. Psychol Sci 2005;16:601-608. [PubMed: 16102062]

49. Premack D, Premack AJ. Infants attribute value +/- to the goal-directed actions of self-propelled objects. J Cognit Neurosci 1997;9:848-856.

50. Gergely G, et al. Rational imitation in preverbal infants. Nature 2002;415:6873.

51. Luo Y. (in press) Do 8-month-olds consider situational constraints when interpreting others' gaze as goal-directed action. Infancy.

52. Liszkowski U, et al. 12- and 18-month-olds point to provide information for others. J Cognit Dev 2006;7:173-187.

53. Luo Y, Baillargeon R. Do 12.5-month-old infants consider what objects others can see when interpreting their actions? Cognition 2007;105:489-512. [PubMed: 17182023]

54. Luo Y, Johnson SC. Recognizing the role of perception in action at 6 months. Dev Sci 2009;12:142149. [PubMed: 19120422]

55. Song H, Baillargeon R. Can 9.5-month-old infants attribute to an actor a disposition to perform a particular action on objects? Acta Psychol 2007;124:79-105.

56. Tomasello M, Haberl K. Understanding attention: 12- and 18-month-olds know what's new for other persons. Dev Psychol 2003;39:906-912. [PubMed: 12952402]

57. Woodward AL. Infants selectively encode the goal object of an actor's reach. Cognition 1998;69:134. [PubMed: 9871370]

58. Onishi KH, et al. 15-month-old infants detect violations in pretend scenarios. Acta Psychol 2007;124:106-128.

59. Leslie AM. Pretending and believing: Issues in the theory of ToMM. Cognition 1994;50:211-238. [PubMed: 8039362]

60. Perner J, Ruffman T. Infants' insight into the mind: How deep? Science 2005;308:214-216. [PubMed: 15821079]

61. Ruffman T, Perner J. Do infants really understand false belief?: Response to Leslie Trends. Cognit Sci 2005;9:462-463.

62. Sirois S, Jackson I. Social cognition in infancy: A critical review of research on higher order abilities. Eur J Dev Psych 2007;4:46-64.

63. Csibra G, Southgate V. Evidence for infants' understanding of false beliefs should not be dismissed. Response to Ruffman and Perner Trends. Cognit Sci 2006;10:4-5.

64. Luo Y, Beck W. Do you see what I see? Infants' reasoning about others' incomplete perceptions. Dev Sci 2010;13:134-142. [PubMed: 20121869] 
65. Haith MM. Who put the cog in infant cognition? Is rich interpretation too costly? Infant Behav Dev 1998;21:167-179.

66. Luo Y, Baillargeon R. When the ordinary seems unexpected: Evidence for incremental physical knowledge in young infants. Cognition 2005;95:297-328. [PubMed: 15788161]

67. He Z, et al. False-belief understanding in 2.5-year-olds: Evidence from change-of-location and unexpected-contents violation-of-expectation tasks. Dev Sci. in press. 
Familiarization trials

Trial 1
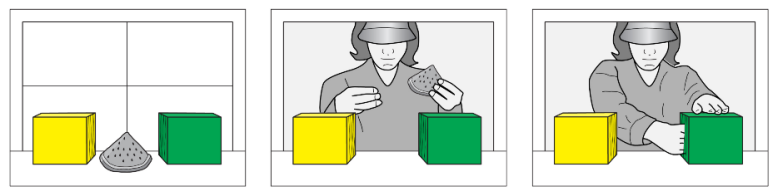

Trials 2 and 3
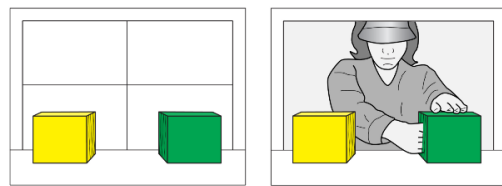

Belief-induction trial

False-belief-green condition
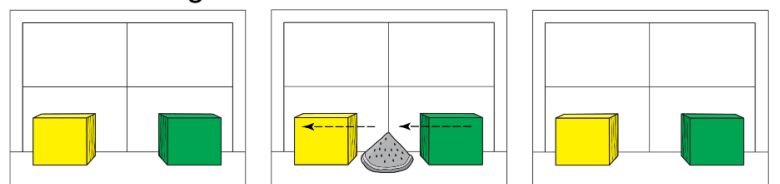

False-belief-yellow condition
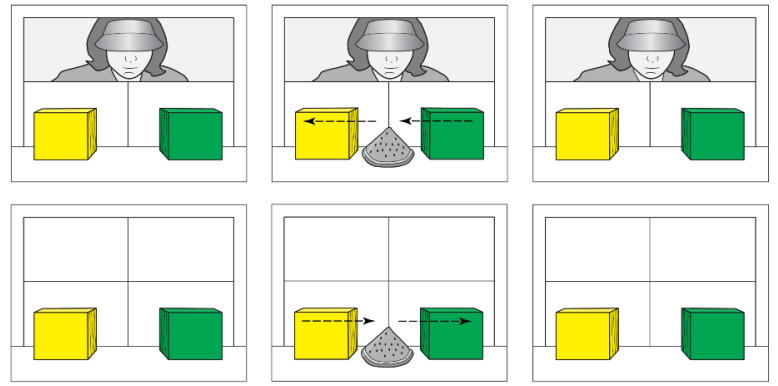

Test trial

Yellow-box event
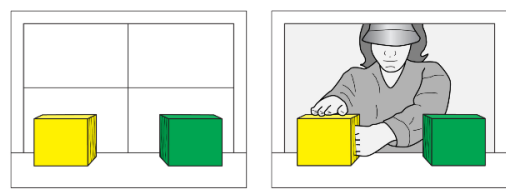

Green-box event
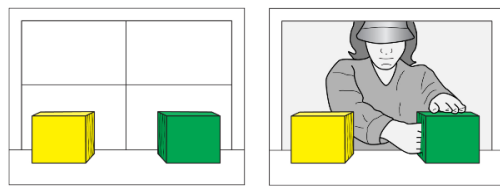

Figure 1.

Can 15-month-olds attribute to an agent a false belief about an object's location? In the falsebelief-green and false-belief-yellow conditions of Onishi and Baillargeon [16], the infants first received three familiarization trials. In trial 1, a toy stood between a yellow and a green box; a female agent entered the apparatus, played with the toy briefly, hid it inside the green box, and then paused, with her hand inside the green box, until the trial ended. In trials 2 and 3 , the agent reached inside the green box, as though to grasp her toy, and then paused. In the beliefinduction trial, the toy either moved from the green to the yellow box in the agent's absence (false-belief-green condition) or moved to the yellow box in the agent's presence but then returned to the green box after she left (false-belief-yellow condition). In the test trial, the agent 
returned, reached inside either the yellow box (yellow-box event) or the green box (green-box event), and then paused. 


\section{Familiarization trials}

\section{Doll condition}

\section{Trials 1 and 2}
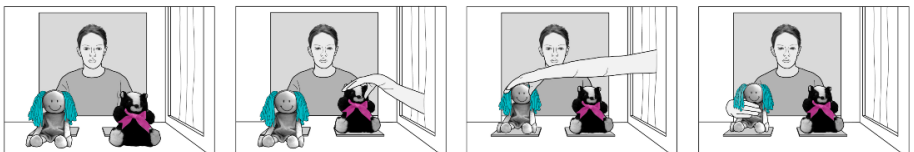

Trials 3 and 4
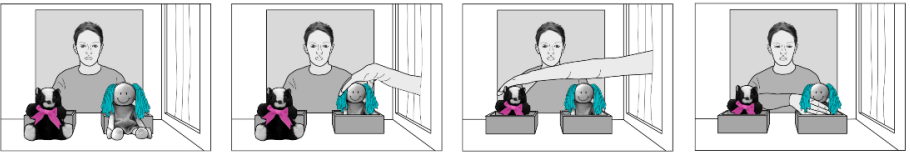

Skunk condition

Trials 1 and 2

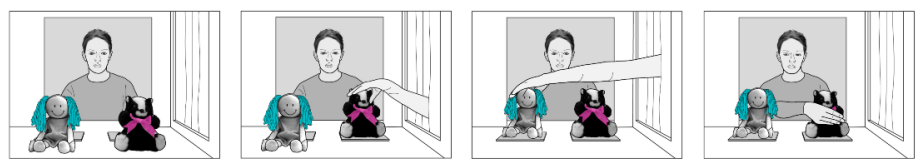

Trials 3 and 4
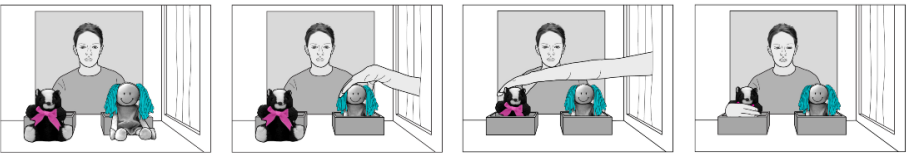

\section{Box-orientation trial}
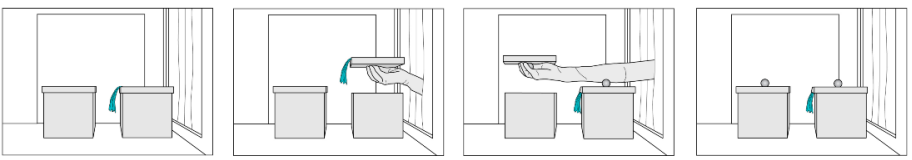

\section{Test trial}
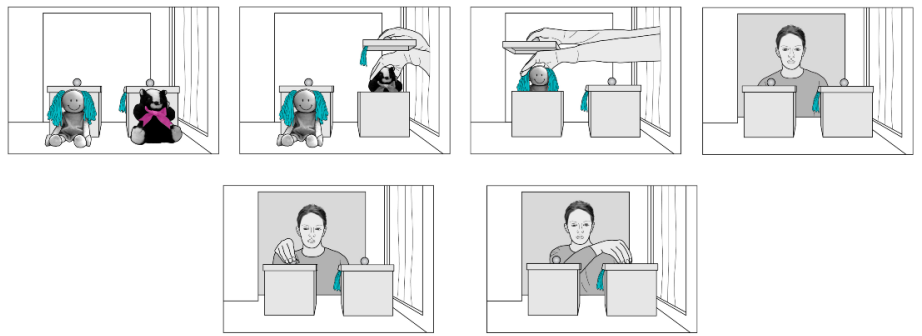

Plain-box event Hair-box event

Figure 2.

Can 14.5-month-olds attribute to an agent a false perception of an object? In the doll and skunk conditions of Song and Baillargeon [21], the infants first received four familiarization trials. In each trial, a female agent sat behind a doll with blue pigtails and a stuffed skunk with a pink bow. An experimenter's gloved hands placed the toys on placemats in trials 1 and 2 and inside shallow containers in trials 3 and 4. The agent always reached for either the doll (doll condition) or the skunk (skunk condition), suggesting that she preferred it over the other toy. In the boxorientation trial, the agent was absent; two large boxes with lids rested on the apparatus floor and the experimenter rotated each lid in turn, demonstrating that the right box's lid had a tuft of blue hair (similar to the doll's) attached to it. At the start of the test trial, the agent was again 
absent; the experimenter hid the doll in the plain box and the skunk in the hair box. The agent then returned, reached for either the plain box (plain-box event) or the hair box (hair-box event), and paused. 


\section{Familiarization trials}

Trials 1 and 2
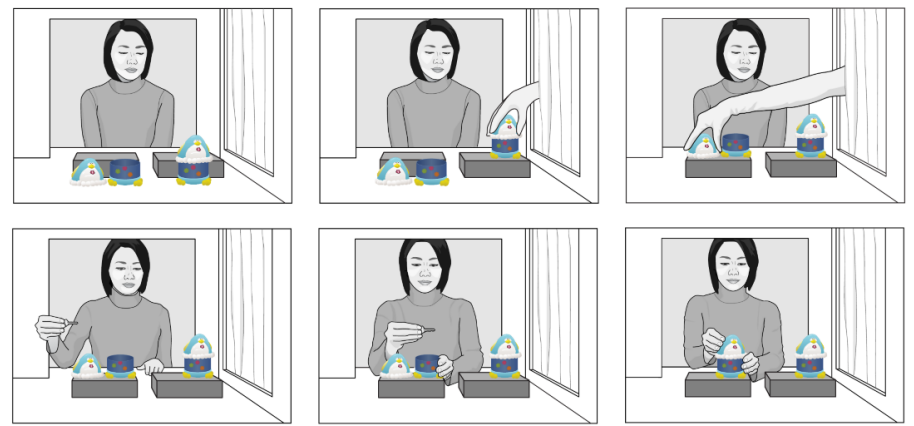

Trials 3 and 4
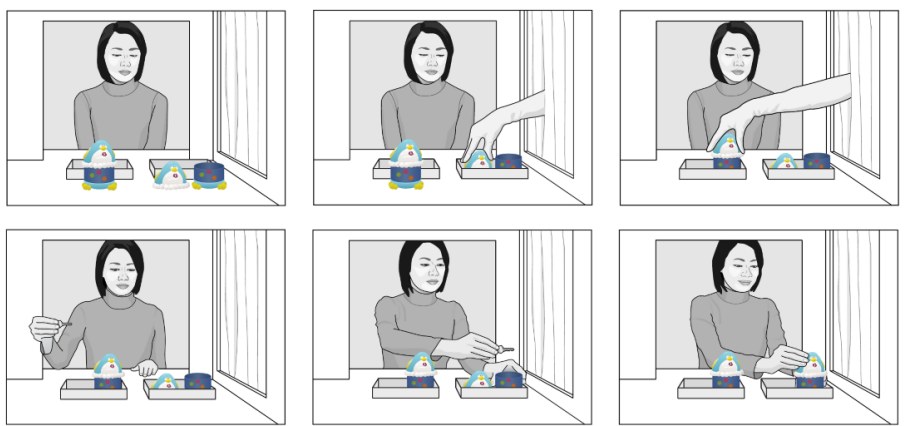

Test trials
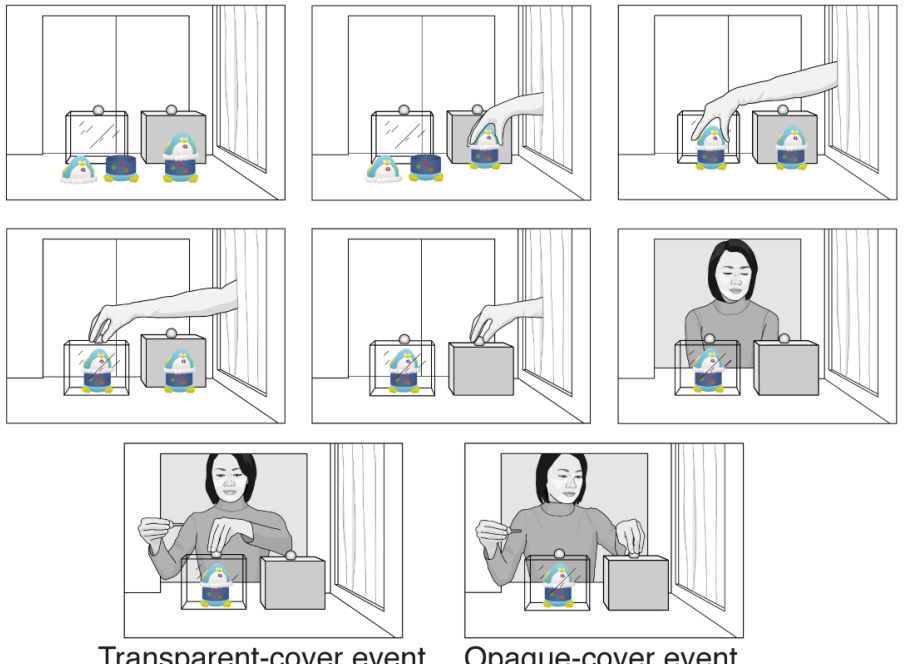

Figure 3.

Can 18-month-olds attribute to an agent a false belief about an object's identity? In the falsebelief experiment of Scott and Baillargeon [4], the infants received four familiarization trials involving two identical toy penguins; one could come apart (2-piece penguin) and one could not (1-piece penguin). As a female agent watched, an experimenter's gloved hands placed the 1-piece penguin and the two pieces of the disassembled 2-piece penguin on platforms in trials 1 and 2 and in shallow containers in trials 3 and 4 . The agent then placed a key in the bottom piece of the 2-piece penguin, stacked the two pieces, and paused. During the test trials, while the agent was absent, the experimenter assembled the 2-piece penguin, covered it with a transparent cover, and then covered the 1-piece penguin with an opaque cover. The agent then 
entered the apparatus with her key, reached for either the transparent cover (transparent-cover event) or the opaque cover (opaque-cover event), and paused. Order of presentation of the two test events was counterbalanced. 


\section{Test trials}
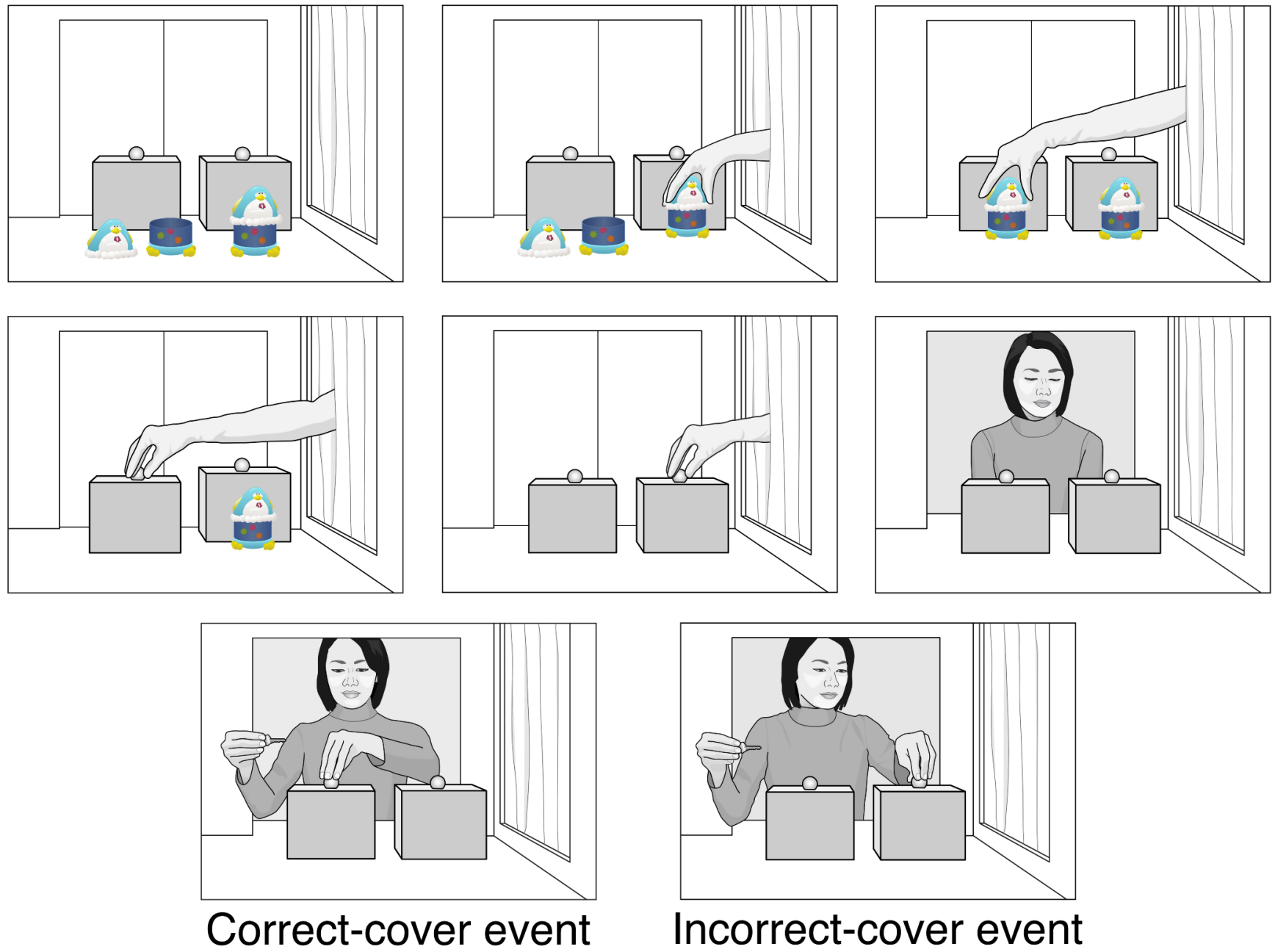

Figure 4.

Do 18-month-olds hold different expectations for an agent who is ignorant as opposed to mistaken about an object's location? In the ignorance experiment of Scott and Baillargeon [4], the infants received the same familiarization trials as in the false-belief experiment (Figure 3 ). The test trials were also similar to those in the false-belief experiment, except that the two covers were both opaque, so that the agent had no basis for determining which cover hid which penguin and was therefore ignorant about the location of the 2-piece penguin. 